\title{
Integrating biodiversity concepts with good governance to support water resources management in South Africa
}

\author{
PJ Ashton ${ }^{1 *}$, MJ Patrick², HM MacKay ${ }^{3}$ and AvB Weaver ${ }^{4}$ \\ ${ }^{1}$ CSIR-Environmentek, PO Box 395, Pretoria 0001, South Africa \\ ${ }^{2}$ CSIR-Environmentek, PO Box 17001, Congella 4013, South Africa \\ ${ }^{3}$ Water Research Commission, Private Bag X03, Gezina 0031, South Africa \\ ${ }^{4}$ CSIR-Environmentek, PO Box 320, Stellenbosch 7999, South Africa
}

\begin{abstract}
Despite recent reforms in its water sector policies and legislation, South Africa's water governance system remains somewhat fragmented because of the need for separate management approaches to address different environmental components of the hydrological cycle. With the responsibility for different components of the hydrological cycle spread amongst several government agencies at different levels of government, integrated management of water across the hydrological cycle will require improved co-operative governance. Examination of existing governance systems and current understandings of biodiversity provides evidence to suggest that a far closer alignment between a particular governance system and the biophysical components and ecological processes comprising a specific environmental system that supports society could significantly enhance our systems of environmental governance. In turn, this would offer society the chance to design water resource management systems that better anticipate, reflect and respond to changes in environmental components and processes within the hydrological cycle. In future, greater emphasis will need to be placed on increased levels of co-operation between relevant governance systems related to water, as well as increased trans-disciplinary research that can better define the links between environmental governance systems and ecological systems.
\end{abstract}

Keywords: biodiversity; governance; ecosystem; integrated water resource management (IWRM); hydrological cycle; policy

\section{Introduction}

The priorities and approaches to management of water resources in South Africa have undergone significant changes in recent years. Prior to 1994, water resource management focused on the development of water resources (i.e. dam construction, interbasin transfers and irrigation schemes) and primarily supported the provision and allocation of water for development in the agricultural, urban and mining sectors (MacKay, 2003). After the first democratic elections in 1994, social equity emerged as a key political priority. In terms of water resource management, this took the form of the challenge to provide basic water and sanitation to the majority of South Africa's population, and to ensure equitable access to water for all people (De Coning and Sherwill, 2004). These political changes informed the process of reform of the policy on water resources and water services, culminating in the promulgation of the Water Services Act (WSA: Republic of South Africa, 1997) and the National Water Act (NWA: Republic of South Africa, 1998).

The NWA recognises that water resources occur in different forms that reflect the different components of the hydrological cycle (aquatic, terrestrial, subterranean, atmospheric and marine), and that integrated management of all these components and aspects of water resources is necessary in order to achieve sustainable use of water for the benefit of all its users (Republic of South Africa, 1998). In order to fulfil this require-

\footnotetext{
* To whom all correspondence should be addressed.

前 +2712 841-3293; fax: +2712 841-2689;

e-mail: pashton@csir.co.za

Received 26 May 2005; accepted in revised form 22 July 2005.
}

ment, a shift in thinking is necessary, from a point where water is seen simply as a commodity to one where water resources are recognised as integral parts of a larger ecosystem. This ecosystem approach requires an understanding of the relationships between the various components of the hydrological cycle and the linkages and inter-relationships between these components. The dynamics of these complex inter-relationships and feedback loops are regulated by ecosystem processes. These ecological processes are important, from a human-needs perspective, for the goods and services they provide. Recognition of the central role that biodiversity plays in maintaining ecological processes and hence in ensuring the maintenance of the flows of ecosystem goods and services on a sustainable basis, is critical to successful water resource management (MacKay et al., 2004).

In addition to understanding biodiversity concepts as they relate to water resource management, it is important to understand the dynamics of the governance systems that are in place, which determine how water resources are managed and how water policies are implemented. Prior to 1994, most water management decisions in South Africa were undertaken by the national government via a centralised, bureaucratic system. This system was virtually inaccessible to the general public and did not allow public participation in decision-making processes (MacKay, 2003). The Constitution of South Africa (Republic of South Africa, 1996) introduced a new approach to public policy and hence to water management decision-making. Two central tenets of the constitution are that people should participate in decision-making processes that affect them, and that national government mandates are most effectively carried out by the lowest appropriate levels of government (Republic of South Africa, 1996). These principles of inclusion and 
subsidiarity support the generic principles of good governance: openness, participation, accountability, effectiveness, coherence, democracy, and integrity (adapted from European Union, 2001).

However, the current water governance system in South Africa is still fragmented and has deep vertical boundaries between the sectors that interact with and/or govern the various components of the hydrological cycle, as well as between scientific organisations working on different components of the hydrological cycle (MacKay and Ashton, 2004). Public sector water management agencies generally do not function in a way that can take into account a highly variable resource base such as water.

Recent years have seen growing international acceptance of a philosophy which recognises that the separation between the ecological system and the governance system is artificial, and that humans should be considered as an integral and interdependent part of the global ecological system (e.g. Western, 1997; Lochner et al., 2003; Young, 2002). From a water resource management perspective, this philosophy offers an intriguing opportunity to enhance our collective understanding of integrated water resource management in South Africa.

In this paper, we explore the potential implications of adopting such an "interdependence" philosophy as a basis for sustainable water resource management in South Africa. First, we consider the concepts of biodiversity and how these relate to ecosystem processes within the hydrological cycle. This is followed by an examination of the concepts and definition of good governance in the context of water resource management. Lastly, we discuss how our understanding of governance and of biodiversity concepts might be better aligned to ensure that water resource management approaches meet the needs of society in South Africa.

\section{Biodiversity concepts}

\section{Introduction}

Biodiversity plays a central role in regulating ecosystem processes in ways that ensure the provision of a wide variety of ecosystem goods and services. Whilst these goods and services represent many of the human benefits that are the basis for social and economic development, they are also highly vulnerable to disturbance and disruption by human activities (Tilman, 2000). The need to maintain the flows of water-related ecosystem goods and services on a sustainable basis underpins water resource management decisions and actions that aim to achieve a balance between resource protection and use (Ashton, 2004). However, the wide array of intricate linkages and inter-relationships between hydrological cycle components, and the implications of external pressures on hydrological cycle components, are seldom fully understood, further complicating the task of water resource management.

\section{What is biodiversity?}

The word 'biodiversity' is an abbreviation of the term 'biological diversity' and its use in this form was first popularised by the ecologist Edward O. Wilson (Wilson, 1988). In essence, biological diversity or 'biodiversity' is a multidimensional and multifaceted concept that refers to the diversity (in terms of both the variety and variability) of all organisms and their habitats, as well as the inter-relationships between organisms and their habitats. Biodiversity is thus an integrating expression of many different spatial levels or scales of organisation, from genes to landscapes, with each level or scale having three different sets of attributes or components, namely: composition, structure and function (Franklin, 1988; Noss, 1990; Chapin et al., 2000; McCann, 2000; Purvis and Hector, 2000).

The various components, processes and linkages through which the multiple roles of biodiversity are influenced and expressed, are shown schematically in Fig. 1. This diagram demonstrates the importance of biodiversity as a determinant or regulator of biotic and abiotic process controls, in addition to energy and material fluxes, through the expression of species traits and species interactions, as well as their vulnerability to human activities (Chapin et al., 2000; Purvis and Hector, 2000; Tilman, 2000).

Figure 1 shows that human activities, motivated by a diverse array of goals and benefits (1), cause a wide range of ecological and environmental changes of global significance (2). These changes occur either directly (3A), or through the regulation of species interactions (3B). Global changes in biogeochemical cycles, land-use patterns and species invasion processes exert a direct influence on biodiversity (4) as well as indirect effects through changes in abiotic processes and ecosystem controls (5). Changes in biodiversity feed back into species invasion processes and the susceptibility of ecosystems to species invasions (6), have a direct effect on species traits (7) and regulate species interactions (8), and contribute directly to ecosystem goods and services (9). In turn, species interactions exert direct effects on species abundance (11), which then influence species traits (12) and feed back into species interactions (13) which may then give rise to a cascade of further effects on species interactions. Species traits have a direct influence on ecosystem goods and services (14), as well as indirect effects, via ecosystem processes (15) or through their influence on direct biotic processes (16A and $16 \mathrm{~B}$ ). In addition, species traits also influence abiotic processes and ecosystem controls (17), which then affect ecosystem processes (18) and ecosystem goods and services (19). Finally, ecosystem processes also feed back into biodiversity (20) to exert an array of additional influences and effects.

\section{Biodiversity concepts and the hydrological cycle in South Africa}

The above explanation of the scope, meaning and implications of the term 'biodiversity' provides an appropriate framework to examine the ways in which this understanding can be applied to aquatic ecosystems, and thence to water resource management. The linkages and inter-relationships between aquatic ecosystems and the broader environment can be explored via the hydrological cycle (Fig. 2). The hydrological cycle links all the components of the broader environment (atmospheric, marine, aquatic, terrestrial and subterranean), and this means that water resources are linked, via the water itself, to all the other components of the broader environment.

Water appears in various forms as a component of all aspects of the environment, reflecting the different phases of the hydrological cycle (Fig. 2):

- In atmospheric ecosystems in or related to South Africa, water is generally in the vapour or liquid form, and occasionally in the solid form as hail or snow.

- In terrestrial ecosystems, water is held in vegetation and/or the unsaturated zone of the soil horizon and becomes part of the evapo-transpiration cycle - the term "green water" has been coined to describe water in this context (Falkenmark, 1999). 


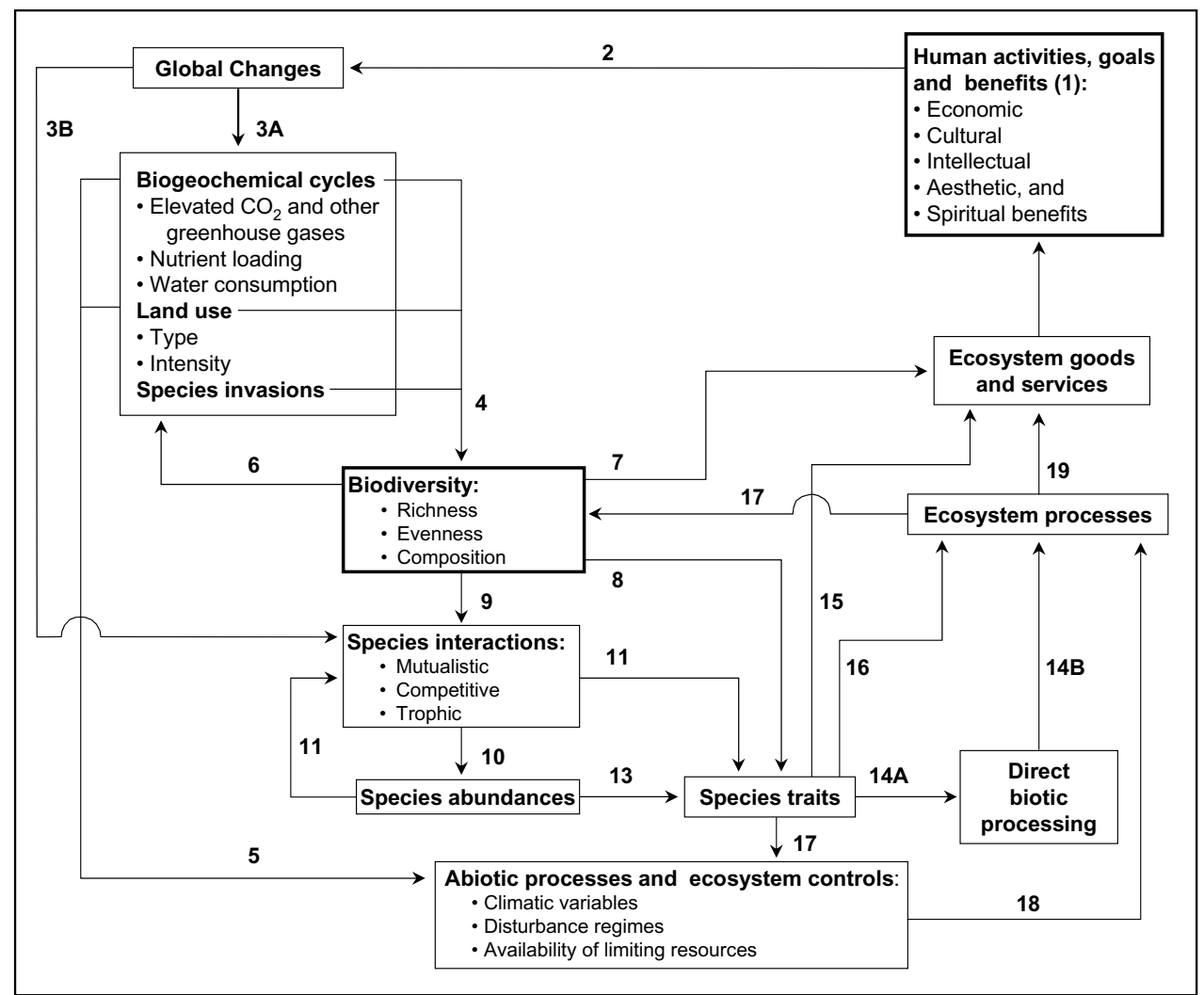

Figure 1

The role of biodiversity in expressing the influences and effects of global change, as well as the mechanisms whereby species traits and their interactions affect ecosystem processes and the delivery of ecosystem goods, services and benefits to society.

Descriptive details of each interaction are outlined in the text (Diagram redrawn from a combination and rearrangement of Figs. 1, 4 and 5 in Chapin et al., 2000).

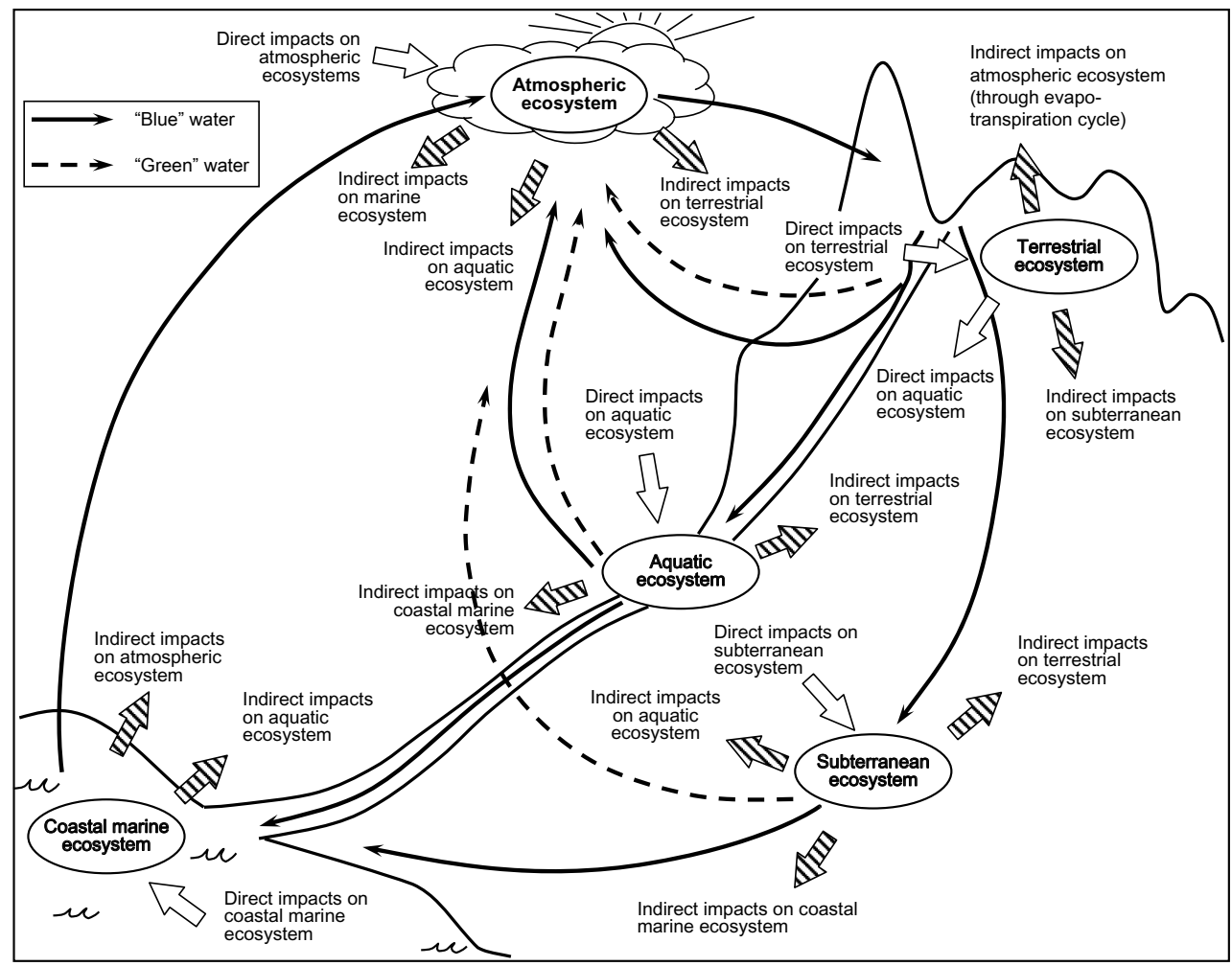

Figure 2

Phases of the hydrological cycle (redrawn from MacKay et al., 2004) 
- Water in aquatic, marine and subterranean ecosystems appears in its liquid form, where it is usually termed "blue water" (Falkenmark, 1999) - this includes water held in aquifers, or in the saturated zone of the soil horizon. In the context of this paper, aquatic ecosystems are those in which water is generally fresh or brackish (but may include hypersaline inland systems). Marine ecosystems include the estuarine and marine aspects of water, and for the purpose of this paper, marine ecosystems are limited to the coastal marine environment.

- Water as ice tends to be common to terrestrial and aquatic ecosystems, and when held in glaciers forms a kind of bridge between terrestrial and aquatic ecosystems. Since there are no glaciers and no permanent snow cover in Southern Africa, this form of water is limited to hail and snow when it is found in the atmosphere.

A disturbance or perturbation in, for example, the atmospheric component of the environment, whether natural or as a result of a direct human-induced impact, can be propagated via indirect impacts to terrestrial, aquatic and marine ecosystems. Figure 2 indicates this, without showing the real-life complexity of feedback loops and second- and third-order effects. The connection between components of the environment is bi-directional, in that direct impacts on the non-water components can affect water, while direct impacts on water (such as water abstraction or effluent discharge) can affect the broader environment as well.

\section{Governance concepts}

\section{Introduction}

The governance system related to the environment is shaped and determined partly by social values and imperatives, and partly by the constraints and opportunities afforded by the ecological system around which an associated governance system has evolved. An effective and "good" governance system is vital to the successful management of water resources, since it can determine and moderate society's response to legislation and policy, and minimise or mitigate the impacts of society on water resources, based on people's inclusion in decision-making processes and understanding of the limits of the ecological systems on which they depend.

\section{What is governance?}

Governance, in the context of governance of water or governance of the environment, includes the full suite of mechanisms for managing water or other natural resources according to objectives that reflect the goals of society. A system of governance within a particular sector ideally should include all three sectors of society:

- Government organisations

- Non-government organisations

- Community or civil society organisations (including the private and commercial sectors)

These sectors are then stratified into different levels, from international through regional, national, provincial, local and neighbourhood. 2004):

There are several levels of governance (MacKay et al.,

- At the highest level, principles are a statement of society's values in relation to a specific issue such as water or envi- ronment. Principles may be universal (e.g. international agreements), national (e.g. the Constitution), or sectoral (e.g. the Water Law Principles).

- Policy at the national level is a statement of intent by government, defining what will be done in order to ensure compliance with the principles (Cloete and Wissink, 2000). Policy can also be set at lower levels, for example at water management area level, where it would be expressed through a catchment management strategy.

- Legislation is the primary tool of government for implementing policy, and sets out how policy objectives will be implemented and enforced

- Regulation usually provides the quantitative or rigorous detail relating to the relevant legislation, and governs everyday activities of all sectors of society. For example, minimum standards for discharges are set in regulation, as are the general authorisations for water use, since the quantitative limits on these could change as new technology becomes available, or as more stringent standards are needed on a site-specific basis. Regulations can be changed more easily than legislation, and can be tailored to specific situations.

- Practice is a general term that covers a wide range of activities, which may not be regulatory, but which nevertheless reflect the principles and support implementation of policy. Practice may include "best practice" tools such as guidelines, which are not necessarily statutory, but which are documented, peer-reviewed and may be adopted by professional practitioners. Practice can include customary or traditional practices, and may be overseen by or from within civil society, whereas policy, legislation and regulation are usually administered by government or an agency to whom authority has been delegated by government. Practice may be influenced by education or advocacy programmes, through the imposition of non-regulatory instruments including economic tools, peer pressure and through voluntary binding agreements between and within sectors of society.

A complete "net" of governance for water, then, would be a three-dimensional system of tools, where the three dimensions are the:

- Level of governance (from principles through to practice)

- Geographic scale of applicability (global, regional, transboundary river basin, national, water management area, provincial, local and neighbourhood levels)

- Responsible agent (government, non-government organisations or civil society groups/individuals)

\section{Good governance}

Given this complex, multi-layered "net" of governance, it is recognised that in order for the functioning of a governance system to be effective, efficient and socially relevant, it should be directed by the principles of good governance. Good governance is founded on the attitudes, ethics, practices and values of society. An example of "good governance" principles is provided in Box 1. It is important to note that the effectiveness of a governance system does not relate in proportion or degree to the inclusion of one or more of the individual principles themselves; rather it is the integration and inclusion of all these principles that underpins the definition of good governance. 


\section{Box 1: Principles of good governance (adapted from European Union, 2001)}

Openness: Governance institutions should work in an open manner. They should actively communicate about what they do and the decisions that are taken. They should use language that is accessible and understandable for the general public.

Participation: The quality, relevance and effectiveness of policies, legislation, regulation and practice, depend on ensuring wide participation throughout the policy chain - from conception to implementation. Improved participation is likely to create more confidence in the end result and in the institutions which deliver and implement policies.

Accountability: Roles in the legislative and executive processes need to be clear. Each institution must define and take responsibility for what it does. There is also a need for greater clarity and responsibility from all those involved in developing and implementing policy at whatever level.

Effectiveness: Policies must be effective and timely, delivering what is needed on the basis of clear objectives, an evaluation of future impact and, where available, of past experience. Effectiveness also depends on implementing policies in a proportionate manner and on taking decisions at the most appropriate level.

Coherence: Policies and actions must be coherent and easily understood. Coherence requires political leadership and a strong responsibility on the part of the institutions to ensure a consistent approach within a complex system.

Democratic: Democratic values in respect of the sharing of power, representation and participation are essential.

Integrity: Leadership that is honest, faithful and diligent, and that protects human rights and freedoms, is critical.

\section{Governance systems and the hydrological cycle in South Africa}

In terms of water resource management, and more specifically legislation and regulations governing the utilisation of water and the impacts on water of human activities, different provisions are generally required to address each different form that water takes in the environment. In part, this reflects the realities of the biophysical environment, where different management approaches are needed for different environmental components of the hydrological cycle. However, importantly, it also reflects the administrative and functional divisions between different sectors. When a number of government agencies have regulatory responsibilities for different components of the environment, and hence for different aspects of the hydrological cycle, problems tend to occur as gaps are left or inconsistencies arise in the overall management and regulatory framework (MacKay and Ashton, 2004).

In South Africa, there are some critical gaps in the governance "net" as far as the whole hydrological cycle is concerned. The principal piece of water resources legislation, the National Water Act (Republic of South Africa, 1998), recognises that water occurs in all phases of the hydrological cycle, and that interventions in one phase of the hydrological cycle can have knock-on effects in other phases. However, the National Water Act only contains regulatory provisions to govern "blue water" in aquatic ecosystems (see Fig. 2), which includes surface water and groundwater (as per the definition of a water resource in the Act). Atmospheric water is dealt with in other legislation, mostly environmental regulation at provincial level, while "green water" is addressed indirectly, and then probably not adequately, by legislation and regulation in the environment, agricultural and land-use planning sectors.

It is interesting to note that the National Water Act, in principle, does not allow the Department of Water Affairs and Forestry (DWAF), the primary water management agency in the country, to undertake integrated catchment management, because that would entail management, control and regulation of activities on the land, as well as those directly affecting water. DWAF is mandated only to undertake "integrated water resource management on a catchment basis", which is not as encompassing as "integrated catchment management". In terms of the South African Constitution, control of land-based activities falls within the responsibilities of several other government departments. In this regard, the only influence which DWAF as the water agency has is the ability to set conditions on the nature, extent and significance of the impacts of land-based activities, at the point where these impacts directly affect water resources, but not necessarily at their origin.

Impacts on water resources may originate from within the water environment itself, for example through discharges of wastewater or abstraction of water, or they may originate in other components of the environment which are under the jurisdiction and management of other administrative sectors, for example the acidification of surface water as a result of emissions of NOx and SOx compounds into the atmosphere. In most cases, where the impact on a water resource originates in another component of the environment, the most efficient place to make a management or regulatory intervention is at the origin of the impact. This may require that an agency other than DWAF make the regulatory intervention, through its own sectoral legislation. However, an intervention in another component of the environment, other than water, will only be effective in terms of the water resource outcome if there is common understanding of the cause-effect relationships between the activity and its impact on water resources, if there is agreement on what kind of intervention to make, and if the policy, legislation and regulations of both agencies are harmonised to ensure that both agencies share common objectives in terms of the final outcome. There are also cases when an activity that is regulated from within the water sector has impacts on other components of the environment; in this case, DWAF may have to make the regulatory intervention on behalf of another administrative sector.

Some Southern African countries, notably Malawi, South Africa and Zambia, have addressed the need for removal of sectoral boundaries by reforming their respective water sector legislation to promote or allow for an explicit ecosystem approach to management of water resources (SADC, 1998). Elsewhere in the Southern African Development Community (SADC) region, other countries are working to align their policy frameworks more closely with the environmental sustainability principles advocated by the regional Water Sector Co-ordinating Unit (SADC, 1998; Hirji et al., 2002; Acreman, 2004; Ashton, 2004). However, despite these welcome policy and legislative reforms, SADC countries still retain much of their original segmented focus on different sources or forms of water and the different sectors of water use (Ashton, 2004). Even South Africa's 


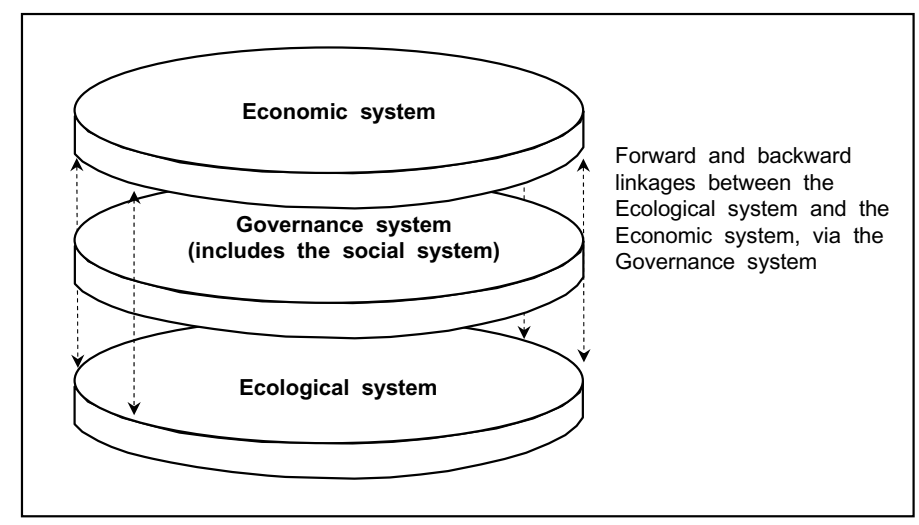

Figure 3

Conceptual diagram, showing the forward and backward linkages between a governance system and the ecological system, where the ecological system is represented by the hydrological cycle (as described in Fig.2)

progressive National Water Act does not address water in all its forms in all phases of the hydrological cycle. Unless this is eventually achieved, either by improved inter-sectoral cooperation or by sectoral reform, then the full protection of water resources, as well as full protection of the environment (since the connections between water and non-water components of the environment are bi-directional), might not be feasible.

In South Africa, the governance of water in the hydrological cycle as a whole will remain distributed amongst several government agencies in different spheres of government, as well as new institutions such as catchment management agencies (CMAs) (MacKay and Ashton, 2004). Integrated management of water across the hydrological cycle will therefore need to be effected through improved co-operative governance, including the government, non-government and civil society sectors. To ensure that this approach is effective, there is a need to review the current governance "net", and where necessary, to fill critical gaps with appropriate interventions, at the appropriate levels.

\section{Aligning the governance system with the eco- logical (biodiversity) system}

There is a rapidly growing body of evidence that human domination of Earth's ecosystems has dramatically transformed large areas of the globe, causing a striking reduction in global biodiversity, and has reduced the capacity of ecosystems to provide society with a sustainable supply of essential goods and services (e.g. Vitousek et al., 1997; Tilman, 2000). This awareness of the implications of biodiversity loss has also been accompanied by increased acceptance of the philosophy that humans are an integral part of the global ecosystem, since this approach better reflects the realities of human dependence on and interdependence with ecological processes (e.g. World Commission on Environment and Development, 1987; Western, 1997; Tilman, 2000). However, for a variety of reasons, these wider philosophical developments are not always fully accepted and many government and legal institutions, at national as well as international level, still adhere to the view that while "society" is dependent upon "the environment", these should be seen as discrete entities and dealt with separately (Hirji et al., 2002; Acreman, 2004). Clearly, this view makes it extremely difficult for water resource management agencies to mainstream the philosophy of integrated water resource management, which requires full integration of all governance and water resource components in order to be successful.

Conceptually, the governance system can be superimposed onto the ecological system: this highlights the linkages between these systems and the economic system (Fig. 3), although still reflecting the perceived separation of humans and ecosystems.
The role of biodiversity in these linkages is not well understood, though we believe it to occur through the effects of changes in biodiversity on the flows of those goods and services that are valuable to society, and hence through its subsequent influence on social and political interactions around resources, such as conflict or co-operation. There is an underlying assumption here that the ecological system sets constraints and limits on society's activities, and these determine whether or not society can survive, develop and prosper. For example, when the socalled "carrying capacity" of a particular ecosystem is exceeded, the consequences for society are often undesirable, though the precise consequences and their sequence or timing are seldom fully predictable or appreciated. In this example, an improved understanding of the governance linkages and their implications should inform the choice between possible tradeoffs that society could make between the short- and long-term implications of biodiversity (ecosystem service) loss and economic or social gain.

Ideally, therefore, a particular governance system should be matched to and aligned with the biophysical and ecological processes occurring within the ecological system that supports a society or community. Decisions about management, use and allocation of natural resources such as water should reflect the realities of the supporting ecological system. While the ideal might be a governance system that is fully integrated with the supporting ecological system, a governance system that is relatively better aligned with the ecological system is at least a significant step forward from the current situation. Importantly, where the available information is considered to be insufficient for a high degree of confidence in the outcome of a particular decision, then a precautionary approach is advised.

Many scholars argue that customary legal and regulatory systems related to the use of natural resources are often closely aligned with local biophysical patterns and processes, and are thus inherently capable of adapting to changes in resource availability (Ashton, 2004). However, since such systems tend to be highly localised and context-specific, it is often difficult, both technically and politically, to expand or upscale them to catchment, regional or even national levels (Van Koppen et al., 2005; Chikozho and Latham, 2005). Nevertheless, there is much to be learned from studies of both customary and conventional or state-centred approaches to natural resource management. The challenge will be to integrate the strengths of both types of approaches into a governance system for water resources, as ecosystems, that is practical, robust and administratively workable.

The primary challenge for South Africa will be to design and implement a governance system for water in the environment that: 
- Is more closely tailored to the structure, function and processes occurring in the ecological system, both within and between compartments of the ecological system

- Can efficiently, effectively and promptly respond to change in the ecological system, either through adapting the governance system itself, or through feeding back into changed behaviour at the individual and/or institutional levels of the governance system

- Encourages management interventions that sustain the longterm health of ecological systems, so that these systems can continue to provide the necessary water-related goods and services to society

Earlier in this paper it was proposed that all environmental components and processes within the hydrological cycle depend on and are regulated by the structural, functional and compositional aspects of biodiversity. Environmental components and processes also respond to, influence and impact on society's decisions and actions. Historically, ecological research has been narrowly focused on separate environmental components within the hydrological cycle, rather than the processes and relationships between them. Thus, these relationships within the hydrological cycle, as well as their role in maintaining flows of water-related goods and services to society, and their vulnerability to change in the broader environment, should be explored in future. Similarly, research on natural resource governance issues has often focused more on social, political and institutional processes within the governance system itself and, until recently, little attention has been paid to the links between associated governance systems and ecological systems (Holling, 2001; Gunderson and Holling, 2002; Folke, 2003; Pollard et al., 2003; Walker et al., 2004).

Internationally, good governance is based on principles such as openness, participation, accountability, coherence, democracy, integrity and effectiveness, as well as social equity and justice (European Union, 2001). In addition, good environmental governance should reflect our best understanding of the structure, functions, processes and variability that typify natural systems (Acreman, 2004). Although there has been considerable development within the field of public and corporate governance, little attention has been paid to the development of good environmental governance systems (Young, 2002). Thus, far greater emphasis needs to be placed on water-related governance within society, and on the design of systems that better anticipate, reflect and respond to changes in environmental components and processes within the hydrological cycle.

\section{Conclusions}

In order to strengthen the capacity to develop and apply ecosystem approaches to water resource management, and to establish and develop governance systems that are both relevant and wellmatched to water resources as ecosystems, the following parallel approaches are considered to be necessary:

- The development of mechanisms and communities of practice that integrate within and between the different specialist disciplines and knowledge bases related to both the biophysical environment and environmental governance systems

- Co-operation between relevant governance sectors, helping to develop and harmonise environmental governance systems related to water. Interactions between these groups to enhance and promote understanding of the role of governance, in support of good environmental governance practices.
Although these interventions or approaches are characterised by a need for integrated research at a high / meta-data analysis level, it is recognised that such research is only possible on the assumption that a sound foundation (of appropriate basic research and data) is in place. This foundation needs to encompass biophysical, ecological, social, political and institutional aspects of the linked ecological-governance-economic systems (Holling, 2001; Young, 2002).

Certainly in South Africa, the foundation of basic research knowledge on aquatic ecosystems was laid during the 1970s and 1980 s, when large national research programmes were in place that focused on whole-system studies, for example work done on the nutrient dynamics of Hartbeespoort Dam (NIWR, 1988). Since then, research has gradually evolved to become more multidisciplinary, where specialists from different disciplines work together on various components of the hydrological cycle, and equally on components of the governance and economic systems. However, to provide knowledge and understanding of the links between ecosystems and governance systems will require truly trans-disciplinary research, involving multiple disciplines (as opposed to specialists from different disciplines working side by side but still relatively independently of each other), and the blending of rigorous quantitative and qualitative investigatory approaches.

From a purely practical perspective, it is challenging to design and execute joint research programmes such as those outlined above. However, these potential problems are far outweighed by the likely benefits that could be gained from the new levels of insight that would underpin fresh and improved approaches and options for governance of water resources. Ultimately, good governance systems need to be aligned closely with each of the water resources that are to be managed. Ideally, this 'net' of good governance should form the core of a water resource management system so that the ideals embodied in the philosophy of integrated water resource management (IWRM) can be attained while meeting the water needs of society.

\section{References}

ACREMAN M (2004) Water and ecology. In: J Dooge and J Selborne (eds.) Water and Ethics. United Nations Educational, Scientific and Cultural Organization (UNESCO), Paris. 35 pp.

ASHTON PJ (2004) Water and development: A southern African perspective. In: J Trottier and P Slack (eds.) Managing Water Resources Past and Present - The 2002 Linacre Lectures. Oxford University Press, Oxford. 149-174.

CHAPIN III FS, ZAVELETA ES, EVINERS VT, NAYLOR RL, VITOUSEK PM, REYNOLDS HL, HOOPER DU, LAVOREL S, SALA OE, HOBBIE SE, MACK MC and DIAZ S (2000) Consequences of changing biodiversity. Nature Insight $\mathbf{4 0 5}$ (No. 6783, 11 May) 234-242.

CLOETE F and WISSINK H (eds.) (2000) Improving Public Policy. Van Schaik, Pretoria. 316 pp.

CHIKOZHO C and LATHAM J (2005) Shona customary practices in the context of water sector reforms in Zimbabwe. Proc. Int. Workshop on African Water Laws: Plural Legislative Frameworks for Rural Water Management in Africa. Johannesburg, 26-28 January 2005. Available (online) at website: www.nri.org/waterlaw/workshop. [Accessed May 2005].

DE CONING C and SHERWILL T (2004) An Assessment of the Water Policy Process in South Africa 1994-2003. Water Research Commission Report No. TT 232/04. Water Research Commission, Pretoria. $57 \mathrm{pp}$.

EUROPEAN UNION (2001) European Governance: A White Paper. Commission of the European Communities, Brussels. Available (online) at website: http://europa.eu.int/comm/governance/white paper/index en.htm [Accessed May 2005]. 
FALKENMARK M (1999) Competing freshwater and ecological services in the river basin perspective - an expanded conceptual framework. In: Proc. SIWI/IWRA Seminar Towards Upstream/Downstream Hydrosolidarity. Swedish International Water Institute, Stockholm.

FOLKE C (2003) Freshwater for resilience: A shift in thinking. Phil. Trans. R. Soc. Lond. 3582027 - 2036.

FRANKLIN JF (1988) Structural and functional diversity in temperate forests. In: EO Wilson, (ed.) Biodiversity. National Academy Press, Washington DC. 166-175.

GUNDERSON LH and HOLLING CS (eds.) (2002) Panarchy: Understanding Transformations in Human and Natural Systems. Island Press, Washington. 507 pp.

HIRJI R, JOHNSON P, MARO P and CHIUTA TM (eds.) (2002) Defining and Mainstreaming Environmental Sustainability in Water Resources Management in Southern Africa. SADC, IUCN, SARDC, World Bank: Maseru, Harare, Washington DC. 318 pp.

HOLLING CS (2001) Understanding the complexity of economic, ecological and social systems. Ecosyst. 4 390-405.

LOCHNER P, WEAVER AvB, GELDERBLOM C, PEART R, SANDWOTH T and FOWKES S (2003) Aligning the diverse: the development of a biodiversity conservation strategy for the Cape Floristic Region. Biol. Cons. 112 29-43.

MACKAY HM (2003) Water policies and practices. In: D Reed and M de Wit (eds.) Towards a Just South Africa: The Political Economy of Natural Resource Wealth. WWF Macroeconomics Programme, Washington. 49-83.

MACKAY HM and ASHTON PJ (2004) A model for co-operative governance in the implementation of cross-sectoral policy: Water policy as an example. Water $S A 30$ (1) 1-8.

MACKAY HM, ASHTON PJ, NEAL MJ and WEAVER AvB (2004) Investment Strategy for the Crosscutting Domain: Water and the Environment. Water Research Commission Report No. KV 148/04. Water Research Commission, Pretoria. 11 pages + appendices.

McCANN KS (2000) The diversity-stability debate. Nature Insight $\mathbf{4 0 5}$ (No. 6783, 11 May) 228-233.

NATIONAL INSTITUTE FOR WATER RESEARCH (NIWR) (1988) Limnology of Hartbeespoort Dam. South African National Scientific Research Programmes Report No. 110, Foundation for Research Development, Pretoria. $175 \mathrm{pp}$.

NOSS RF (1990) Indicators for monitoring biodiversity. Cons. Biol. 4 355-364.

POLLARD S, SHACKLETON C and CARRUTHERS J (2003) Beyond the fence: People and the lowveld landscape. In: JT du Toit, KH
Rogers and HC Biggs (eds.) The Kruger Experience. Island Press. Washington D.C. 519 pp.

PURVIS A and HECTOR A (2000) Getting the measure of biodiversity. Nature Insight 405 (No. 6783, 11 May) 212-219.

REPUBLIC OF SOUTH AFRICA (1996) The Constitution of the Republic of South Africa (Act No. 108 of 1996). Government of the Republic of South Africa, Pretoria.

REPUBLIC OF SOUTH AFRICA (1997) Water Services Act (Act No. 108 of 1997). Department of Water Affairs and Forestry, Pretoria.

REPUBLIC OF SOUTH AFRICA (1998) National Water Act (Act No. 36 of 1998). Department of Water Affairs and Forestry, Pretoria.

SOUTHERN AFRICAN DEVELOPMENT COMMUNITY (SADC) (1998) Regional Strategic Action Plan (RSAP) for Integrated Water Resources Development and Management in the SADC Countries (1999-2004). Summary Report. SADC Water Sector Co-ordinating Unit, Maseru, Lesotho.

TILMAN D (2000) Causes, consequences and ethics of biodiversity. Nature Insight 405 (No. 6783, 11 May) 208-211.

VAN KOPPEN B, BUTTERWORTH J, JUMA I, MAGANGA F, LATHAM J, CHIKOZHO C and MORRIS M (2005) Legal pluralism and rural water management: objectives, definitions and issues. Proc. Int. Workshop on African Water Laws: Plural Legislative Frameworks for Rural Water Management in Africa. Johannesburg, 26028 January 2005. Available (online) at website: Www.nri.org, waterlaw/workshop. [Accessed May 2005].

VITOUSEK PM, MOONEY HA, LUBCHENCO J and MELILLO JM (1997) Human domination of earth's ecosystems. Sci. 277 494-199.

WALKER B, HOLLING CS, CARPENTER SR and KINZIG A (2004) Resilience, adaptability and transformability in social-ecological systems. Ecology and Society 9(2) 5. Available (online) at website: http//www.ecologyandsociety.org/vol9/iss2/art5 [Accessed October 2004].

WESTERN D (1997) In the Dust of Kilimanjaro. Island Press, Washington D.C. 297 pp.

WILSON EO (1988) The current state of biodiversity. In: EO Wilson (ed.) Biodiversity. National Academy Press, Washington D.C. 3-18.

WORLD COMMISSION ON ENVIRONMENT AND DEVELOPMENT (WCED) (1987) Our Common Future. Oxford University Press, New York.

YOUNG OR (2002) Matching Institutions and Ecosystems: The Problem of Fit. Institute on International Environmental Governance, Dartmouth College, USA. 31 pp. 